\title{
InCReased LeVels of Anti-Glycan Antibodies in Patients WITH CYSTIC FibROSIS
}

\author{
T. O. Hirche ${ }^{1}$, J. Stein ${ }^{2}$, H. Hirche 3 , J. Hausmann 4 , T. O. Wagner 4 , F. Behrens 4 , O. Schröder ${ }^{4}$ \\ ${ }^{1}$ Department of Pulmonary Medicine, German Clinic for Diagnostics (DKD), Wiesbaden, Germany \\ ${ }^{2}$ Department of Gastroenterology, Elisabethen Hospital, Frankfurt, Germany \\ ${ }^{3}$ Institute for Medical Informatics, Biometry and Epidemiology, University of Duisburg-Essen, Essen, Germany \\ ${ }^{4}$ Department of Internal Medicine, Johann Wolfgang Goethe-University Hospital, Frankfurt, Germany
}

\begin{abstract}
Background: The prevalence of Crohn's disease (CD) is increased in patients with cystic fibrosis (CF). AntiSaccharomyces cerevisiae antibodies (ASCA) have been suggested as a screening tool to detect CD in CF. Recently, several new anti-glycan antibodies have been reported in CD.

Materials and methods: The sera of 119 CF patients of various age groups were prospectively screened for ASCA type IgG (gASCA), anti-laminaribioside carbohydrate IgG antibodies (ALCA), anti-chitobioside carbohydrate IgA antibodies (ACCA), and anti-mannobioside carbohydrate IgG antibodies (AMCA). The frequency of these anti-glycan antibodies was then compared in patients with $\mathrm{CD}$, ulcerative colitis, rheumatoid arthritis and healthy volunteers.

Results: A significant number of CF patients were positive for gASCA (51.3\% [41.6-60.6]) and up to three other anti-glycan antibodies concurrently. Serum levels of anti-glycan antibodies in CF and CD were not related to parameters of inflammation. Despite the well-documented difference in clinical course between male and female CF patients no gender difference of anti-glycan antibodies was found. In contrast, there was a significant positive correlation between anti-glycan markers and age in CF patients.

Conclusions: Our findings demonstrate for the first time the increased frequency of a panel of anti-glycan antibodies in CF and provide a link between the presence of these serological biomarkers and patient's age. Anti-glycan antibody profiling may therefore become a valuable tool in the care of patients with $\mathrm{CF}$.
\end{abstract}

Key words: cystic fibrosis, crohn's disease, anti-glycan antibodies, ASCA

\section{INTRODUCTION}

Cystic fibrosis (CF) is the most common autosomal recessive inherited disease of Caucasians with an incidence of $1: 2000$ to $1: 3000$ [1]. The primary cellular defect, the reduced expression of the cystic fibrosis transmembrane conductance regulator (CFTR), leading to diminished chloride secretion, is present in all epithelial cells of endodermal and mesodermal origin including the intestine [2]. Typical gastrointestinal complications of CF may manifest as meconium ileus at birth or distal intestinal obstruction syndrome (DIOS) primarily occurring in adolescents and adults $[3,4]$. Other gastrointestinal impairment may involve constipation, intussusception, and rectal prolapse [3, 4]. However, many patients with CF have abdominal symptoms which cannot be categorized into the above mentioned conditions.

Crohn's disease (CD) is a chronic inflammatory bowel disease (IBD) in which non-pathogenic, commensal intestinal bacteria are thought to trigger a chronic dysregulated immune response against mucosal barrier function (for review see [5]). In a prospective multicentre study involving more than $11000 \mathrm{CF}$ patients the prevalence of CD was reported to be 1:453, a rate which is 17 times that of the control group [6]. Due to a lack of a specific test for CD and overlapping clinical features of both disorders the identification of CD in CF patients is hampered.

In recent years much effort has been made to develop biomarkers for diagnosis, stratification, and predicting of various diseases including CD. The major serologic markers for $\mathrm{CD}$ are anti-Saccharomyces cerevisiae antibodies (ASCA), which have been identified in up to $60 \%$ of adults and children with CD [7, 8]. ASCA belong to the group of anti-glycan antibodies. Glycan is a generic term describing molecules with glycosidic bonds, including mono-, oligo-, and polysaccarides as well as carbohydrates. They are predominant cell surface components of various types of cells including erythrocytes, immune cells, and microorganisms leading to a variety of anti-glycan antibodies of all classes (for review see [9]). Besides ASCA, three novel anti-glycan antibodies were recently identified and associated with CD: anti-laminaribioside carbohydrate IgG antibodies (ALCA), anti-chitobioside carbohydrate $\operatorname{IgA}$ antibodies (ACCA), and anti-mannobioside carbohydrate IgG antibodies (AMCA). Recent results have demonstrated that such serological markers provide a panel that complement ASCA for disease diagnosis with a prevalence of 19 to $40 \%$ in CD patients [10-12].

The potential use of ASCA as a tool in screening patients with $\mathrm{CF}$ for $\mathrm{CD}$ was suggested previously by demonstrating a higher frequency of ASCA seropositivity particularly in children with $\mathrm{CF}$ as compared to 
the general population [13]. In this study, we aimed at expanding the knowledge of the prevalence of antiglycan antibodies in both, children and adults with CF.

\section{SubJECTS AND Methods}

\section{STUdy POPUlation}

CF patients attending Frankfurt university CF centre between May 2007 and October 2008 were prospectively enrolled in the study. Diagnosis of CF was confirmed by a sweet test (pilocarpin iontophoresis) and/or genetic testing in each case. Patient characteristics (age, gender) and routine laboratory parameters, including markers of inflammation (leukocyte count, C-reactive protein [CRP]), were recorded. Individuals who presented with symptoms of acute exacerbation and/or inflammation were excluded from the study. As a control, patients with CD, ulcerative colitis (UC), rheumatoid arthritis (RA), and healthy volunteers were also tested for seropositivity of anti-glycan antibodies. Informed consent was given by all patients and the study was performed in accordance with the principles of the 1983 Declaration of Helsinki.

\section{Measurement of Anti-gLyCan Antibodies}

A panel of anti-glycan antibodies (ACC, ALCA, AMCA, gASCA) was determined by indirect solid phase enzyme-linked immunosorbent assays (IBDX, Glycominds, Lod, Israel) following modification of previously described protocols [14]. Briefly, blood samples $(10 \mathrm{ml}$, containing heparin) from patients and controls were collected by venipuncture as prescribed by local regulatory requirements. Samples were separated immediately from red blood cells and stored at $80^{\circ} \mathrm{C}$ until assayed. Serum samples $(10 \mu \mathrm{l})$ were mixed with sample diluent $(1: 100)$. Next, $50 \mu$ l of diluted samples and pre-diluted controls/calibrator were incubated for 30 minutes with mannobioside immobilized in microtiter wells. After thorough washing, plates were incubated for 30 minutes with enzyme labelled (HRP) anti-human IgG. Next, unbound serum conjugate was removed by washing and chromogenic substrate (TMB) added for 15 minutes (ALCA, gASCA) or 30 minutes (AMCA, ACCA). Subsequently, reactions were terminated by addition of HRP stop solution and absorbance's of calibrator, samples and controls were evaluated spectrophotometrically (OD 450 $\mathrm{nm})$. The results correlate with the quantity of antibody present in the patient sample in a non-linear fashion, a cut off threshold of $50 \mathrm{U} / \mathrm{ml}$ for each antiglycan antibody was established empirically.

\section{Statitical Methods}

Logarithmic transformation was used for sufficient normal distribution of clinical and biochemical variables which were expressed as mean \pm SEM or as median with quartiles (Q25\% and Q75\%), when appropriate. The correlation of anti-glycan antibodies in patients with CD was done by Spearman's rank correlation coefficient. Diagnostic parameters sensitivity (SE), specificity (SP), positive predictive value (PPV), negative predictive value (NPV), and accuracy were calculated for prediction of CD by anti-glycan antibodies using endoscopy and histological examination as gold standard. In a multiple logistic regression model with stepwise forward selection of factors associated with CD, age, gender, leucocyte count, CRP, and anti-glycan antibodies were included as potential predictors. Comparison of groups was done by analyses of variance (ANOVA) with multiple Scheffe test, if necessary. Fishers exact test was used for categorical variables. Assessment of statistical significance was predefined with a two-sided level of $2 \alpha<0.05$. Resulting $\mathrm{p}$-values are presented descriptively with Bonferroni's adjustment for multiple testing. All statistical calculations were done by SAS Software, Version 9.1, SAS Institute Inc., Cary, USA.

\section{RESULTS}

In this study, $119 \mathrm{CF}$ patients (70 children, 49 adults, mean age \pm SD: $23.8 \pm 11$ years) without signs of acute exacerbation were included. For controls, $34 \mathrm{pa}-$ tients with $\mathrm{CD}$ (mean age $\pm \mathrm{SD}: 41.1 \pm 16$ years), 11 patients with ulcerative colitis (mean age \pm SD: $38.1 \pm$ 17 years), 22 patients with rheumatoid arthritis (mean age \pm SD: $57.9 \pm 13$ years), as well as 16 healthy volunteers (mean age \pm SD: $30.9 \pm 5$ years) were included (Table 1). Serology associated with CD (e.g., at least one of the anti-glycan markers $\geq 50 \mathrm{U} / \mathrm{ml}$ ) was frequently observed in patients with previously determined CD, but rarely positive in the control groups. In contrast, levels of anti-glycan antibodies, particularly gASCA, were markedly increased in CF patients compared to the controls $(\mathrm{p}<0.001)$ (Fig. 1).

All four anti-glycan antibodies evaluated correlated univariately with $\mathrm{CD}$ with rank correlation coefficients of $\mathrm{rs}=0.39(\mathrm{p}<0.001), 0.36(\mathrm{p}<0.001), 0.17(\mathrm{p}>$ $0.12)$, and 0.66 ( $\mathrm{p}<0.001)$ for ALCA, AMCA, ACCA, and gASCA, respectively. However, when all demographic and serological parameters were entered in a multivariate logistic stepwise regression model, gASCA proved to be the only significant predictor associated with $\mathrm{CD}$ with a high odds ratio $[95 \% \mathrm{CI}$ of 27 [8-93] $(\mathrm{p}<0.001)$. gASCA alone predicted CD with

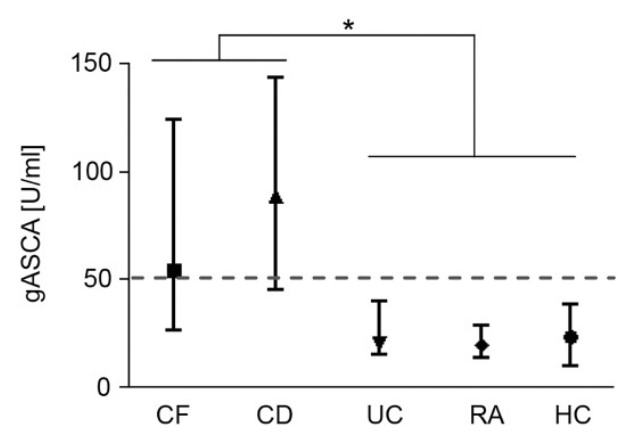

Fig. 1. Increased serum levels of gASCA in CF patients. Shown are gASCA serum levels (median, Q25\%, Q75\%) for patients with cystic fibrosis (CF), Crohn's disease (CD), ulcerative colitis (UC), rheumatoid arthritis (RA), as well as healthy volunteers (HC). Dashed line indicates threshold for positive anti-glycan titer $(\geq 50 \mathrm{U} / \mathrm{ml})$. Asterisk indicates statistical significance in the difference between CF and CD vs. UC, RA, and HC ( $p<0.02$, ANOVA and Scheffe test). 
Table 1. Comparison of demographic and serological parameters used in this study.

\begin{tabular}{|c|c|c|c|c|c|c|}
\hline Parameter & CF $(n=119)$ & $\mathrm{CD}(\mathrm{n}=34)$ & $\mathrm{UC}(\mathrm{n}=11)$ & $R A(n=22)$ & HC $(n=16)$ & $\mathrm{p}<0.05$ \\
\hline Gender $(\mathrm{m} / \mathrm{f})$ & $67 / 52$ & $14 / 20$ & $3 / 8$ & $5 / 17$ & $10 / 6$ & n.s. \\
\hline $\begin{array}{l}\text { Age } \\
\text { (years) }\end{array}$ & $\begin{array}{c}23.0 \\
{[16,33]^{*}}\end{array}$ & $\begin{array}{c}36.5 \\
{[29,58]}\end{array}$ & $\begin{array}{c}30.0 \\
{[25,61]}\end{array}$ & $\begin{array}{c}57.5 \\
{[49,64]}\end{array}$ & $\begin{array}{c}29.0 \\
{[28,34]}\end{array}$ & RA vs. all \\
\hline $\begin{array}{l}\text { WBC } \\
(/ \mathrm{nl})\end{array}$ & $\begin{array}{c}8.9 \\
{[7,11]}\end{array}$ & $\begin{array}{c}8.5 \\
{[5,10]}\end{array}$ & $\begin{array}{c}8.5 \\
{[6,11]}\end{array}$ & $\begin{array}{c}8.0 \\
{[6,11]}\end{array}$ & n.d. & n.s. \\
\hline $\begin{array}{l}\text { CRP } \\
(\mathrm{mg} / \mathrm{dl})\end{array}$ & $\begin{array}{c}0.3 \\
{[0.1,1.0]}\end{array}$ & $\begin{array}{c}0.4 \\
{[0.1,1.2]}\end{array}$ & $\begin{array}{c}0.3 \\
{[0.05,1,0]}\end{array}$ & $\begin{array}{c}0.3 \\
{[0.1,3.9]}\end{array}$ & n.d. & n.s. \\
\hline $\begin{array}{l}\text { ALCA } \\
(\mathrm{U} / \mathrm{ml})\end{array}$ & $\begin{array}{c}18.8 \\
{[12,32]}\end{array}$ & $\begin{array}{c}30.8 \\
{[21,50]}\end{array}$ & $\begin{array}{c}16.3 \\
{[12,29]}\end{array}$ & $\begin{array}{c}14.3 \\
{[9,20]}\end{array}$ & $\begin{array}{c}23.3 \\
{[19,31]}\end{array}$ & $\mathrm{CD}$ vs. RA \\
\hline $\begin{array}{l}\text { ACCA } \\
(\mathrm{U} / \mathrm{ml})\end{array}$ & $\begin{array}{c}22.2 \\
{[17,39]}\end{array}$ & $\begin{array}{c}35.4 \\
{[22,47]}\end{array}$ & $\begin{array}{c}30.0 \\
{[16,40]}\end{array}$ & $\begin{array}{c}24.1 \\
{[17,31]}\end{array}$ & $\begin{array}{c}35.6 \\
{[27,42]}\end{array}$ & n.s. \\
\hline $\begin{array}{l}\text { AMCA } \\
(\mathrm{U} / \mathrm{ml})\end{array}$ & $\begin{array}{c}29.9 \\
{[23,46]}\end{array}$ & $\begin{array}{c}32.8 \\
{[25,55]}\end{array}$ & $\begin{array}{c}23.1 \\
{[16,26]}\end{array}$ & $\begin{array}{c}23.8 \\
{[20,30]}\end{array}$ & $\begin{array}{c}30.6 \\
{[20,40]}\end{array}$ & n.s. \\
\hline $\begin{array}{l}\text { gASCA } \\
\text { (U/ml) }\end{array}$ & $\begin{array}{c}55.6 \\
{[27,124]}\end{array}$ & $\begin{array}{c}88.9 \\
{[51,143]}\end{array}$ & $\begin{array}{c}20.5 \\
{[15,40]}\end{array}$ & $\begin{array}{c}20.0 \\
{[14,27]}\end{array}$ & $\begin{array}{c}23.0 \\
{[10,38]}\end{array}$ & $\begin{array}{c}\text { CD vs. } \\
\text { CU,RA,HC }\end{array}$ \\
\hline
\end{tabular}

Continuous variables: median [Q25\%, Q75\%], WBC = white blood cell count; CRP = C-reactive protein; CF = cystic fibrosis; $\mathrm{CD}=$ Crohn's disease; $\mathrm{UC}=$ ulcerative colitis; RA $=$ rheumatoid arthritis; $\mathrm{HC}=$ healthy volunteers. Differences between groups were compared by ANOVA with Scheffe-Test or Fisher's exact test $(*)$ with Bonferroni.

Table 2. Performance characteristics of anti-glycan antibodies for detection of patients with Crohn's disease.

\begin{tabular}{lrrrrr}
\hline & SE & \multicolumn{1}{c}{ SP } & PPV & NPV & ACC \\
\hline gASCA only & 76.5 & 91.8 & 86.7 & 84.9 & 85.5 \\
gASCA+1Ab & 41.2 & 95.9 & 87.5 & 70.1 & 73.5 \\
gASCA+2Ab & 17.6 & 100.0 & 100.0 & 63.6 & 66.3 \\
gASCA+3Ab & 2.9 & 100.0 & 100.0 & 59.8 & 60.2 \\
\hline
\end{tabular}

$\mathrm{SE}=$ sensitivity; $\mathrm{SP}=$ specificity $\mathrm{PPV}=$ positive predictive value; $\mathrm{NPV}=$ negative predictive value $\mathrm{ACC}=\mathrm{accuracy} ; \mathrm{Ab}=$ anti-glycan antibodies (ACCA, ALCA, AMCA). Sera positive antibody titers were defined as $\geq 50 \mathrm{U} / \mathrm{ml}$.

good specificity $(91,8 \%)$, but only moderate sensitivity $(76 \%)$ and accuracy $(85,5 \%)$. Combination of anti-glycan antibodies allowed to increase specificity to up to $100 \%$, however, this resulted in poor results of other operative test characteristics (Table 2).

Previously, presence of multiple anti-glycan antibodies was found to be associated with a more complicated and severe course in $C D$ with a hazard ratio of 2 to 4 [11]. While several patients with CD were found to be positive for up to all four anti-glycan markers tested in this study, none of the controls were positive for more than two. In contrast, a significant number of $\mathrm{CF}$ patients were positive for gASCA (51.3\% (41.6-60.6)) and up to three other anti-glycan antibodies concurrently, suggesting a close pathophysiological relation between CF and CD (Fig. 2a-e).

Serum levels of anti-glycan antibodies in CF and CD disease were not related to parameters of inflammation (data not shown). Despite the well documented difference in clinical course between male and female CF patients [14] we found no gender difference of anti-glycan antibodies (male: $53,7 \%$ (41-66) vs. female: 48,0\% (34-62)) (Fig. 3). In contrast, there was a moderate, but highly significant positive correlation between anti-glycan markers and age in CF patients. This phenomenon was particularly prominent for gASCA with Spearmann's correlation coefficient rs = 0.39 ( $p<0.001$ ), but also remained present when combinations of multiple anti-glycan antibodies were analysed (Figs. 4 and 5).

\section{Discussion}

Besides the established role of ASCA in CD, systematic screening for other anti-glycan antibodies using glycan array has lead to the discovery of novel biomarkers that may be associated with IBD. These include gASCA, ACCA, ALCA, and AMCA. There is mounting evidence suggesting not only a diagnosing and differentiating capability of these biomarkers in IBD. Two recent studies demonstrated that seropositivity for the anti-glycan antibodies is associated with early disease onset, complicated disease behaviour, and IBD-related surgery $[11,15]$. It appears that a combination of these biomarkers is superior to their single use. Finally, like ASCA ACCA, ALCA, and AMCA have been found to be linked to genetic susceptibility. Several studies clearly demonstrated an association be- 


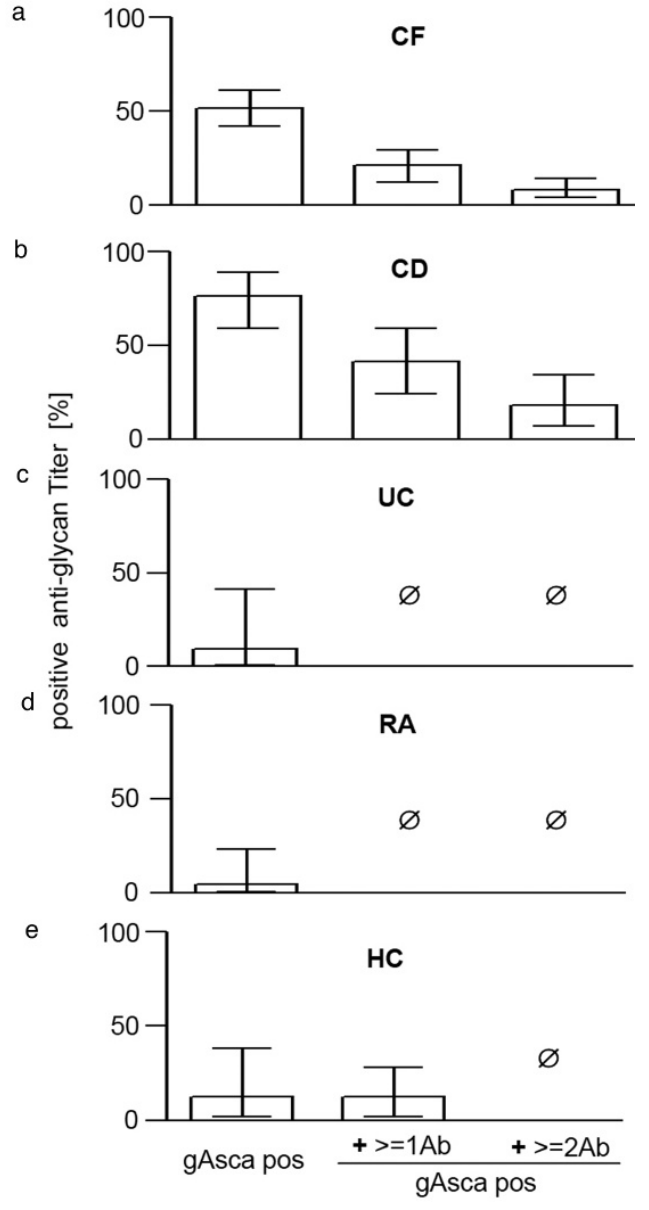

Fig. 2. Multiple anti-glycan antibodies detectable in CF patients. a-e, Comparison of anti-glycan antibodies ( $\%$ of sera positive results \pm CI $95 \%$ ) for patients with cystic fibrosis $(\mathrm{CF}, \mathrm{a})$, Crohn's disease $(\mathrm{CD}, \mathrm{b})$, ulcerative colitis (UC, c), rheumatoid arthritis (RA, d), as well as healthy volunteers (HC, e). Positive anti-glycan titer were defined as $\geq 50 \mathrm{U} / \mathrm{ml}$. $\mathrm{X}$-axis indicates patients positive for gASCA alone, or positive for gASCA $+\geq 1 \mathrm{Ab}$ or gASCA $+\geq 2 \mathrm{Ab}$ at the time, respectively. Patients positive for gASCA and $\geq 2$ anti-glycan markers were only found in CF and CD, but not in any of the other groups.

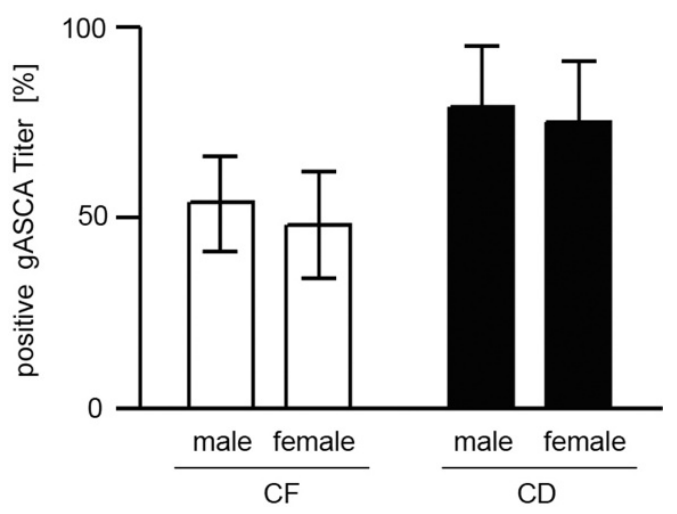

Fig. 3. Serum levels of gASCA are not dependent on gender in CF patients. Comparison of gASCA ( $\%$ of sera positive results with CI 95\%) between male and female patients with cystic fibrosis (CF) or Crohn's disease (CD). Positive anti-glycan titer were defined as $\geq 50 \mathrm{U} / \mathrm{ml}$.

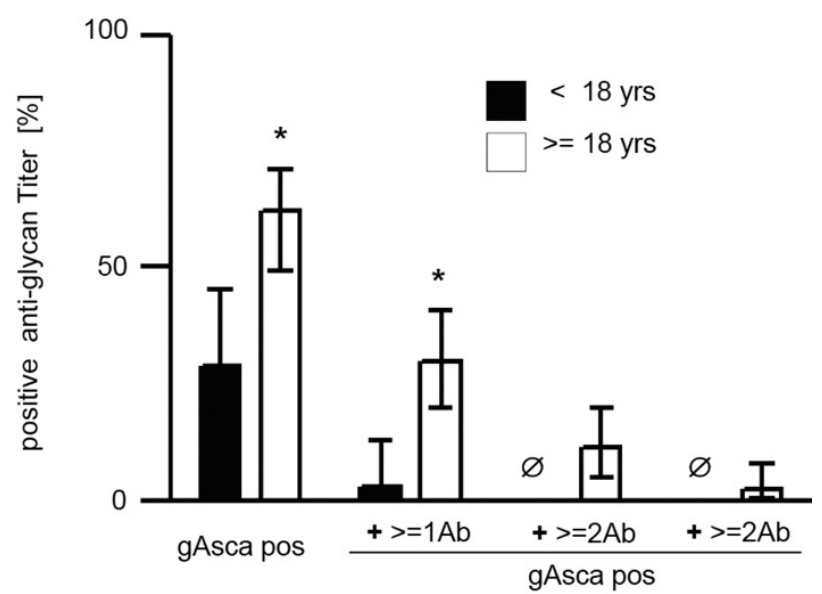

Fig. 4. Increased levels of anti-glycan antibodies in adults patients with CF. Comparison of anti-glycan antibodies $(\%$ of sera positive results with CI95\%) between children and adult patients with cystic fibrosis (CF). Positive anti glycan titer were defined as $\geq 50 \mathrm{U} / \mathrm{ml}$. X-axis indicates patients positive for gASCA only (gASCA pos), or gASCA and additional antiglycan antibodies at the time $(+\geq 1 \mathrm{Ab} ; \geq 2 \mathrm{Ab}, \geq 3 \mathrm{Ab})$. Asterisks indicate statistical significance for difference between CF children and adults $(p<0.002$, Fisher's exact test after Bonferroni's adjustment).

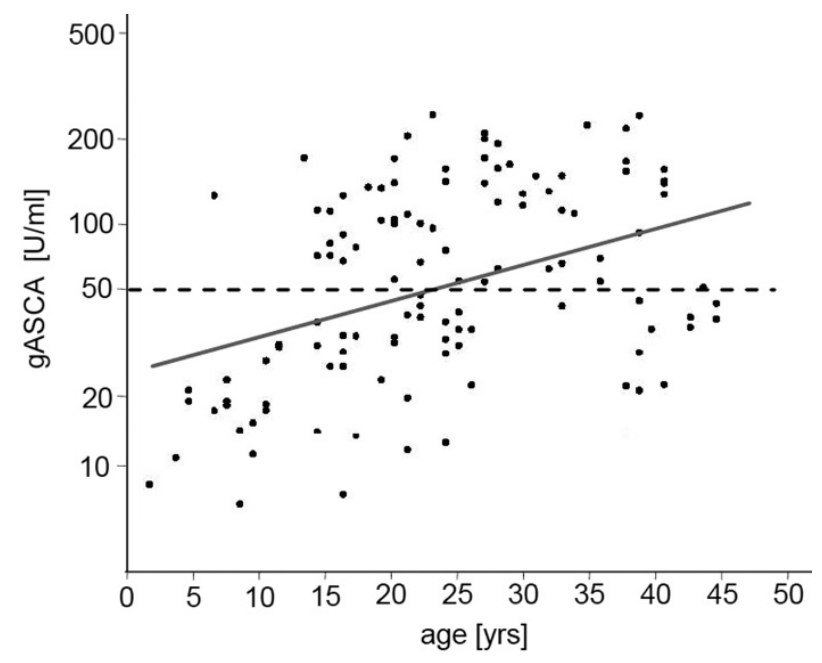

Fig. 5. Serum levels of gASCA are increasing with age in CF patients. Scatter-plot of gASCA according to age of CF patients. Bold line represents line of regression $(\log$ gASCA $=$ $1.406+0.136 \mathrm{x}$ age). Dashed line indicates threshold for positive anti-glycan titer $\geq 50 \mathrm{U} / \mathrm{ml}$ ). Correlation between gAS$\mathrm{CA}$ and age was statistically significant (Spearman's rank correlation $\mathrm{rs}=0.39, \mathrm{p}<0.001)$.

tween antimicrobial formation and the carriage of mutations of innate immune response genes such as NOD2/CARD15 or the toll like receptors (TLR) 2 and $4[15,16]$.

ASCA have previously also been described in CF. In a prospective evaluation among young CF patients aged 2 to 21 seropositivity for ASCA was found in 17 out of 82 patients $(20.7 \%)$. Eight patients exhibited antibodies of the $\operatorname{IgA}$ class, six had $\operatorname{IgG}$ antibodies and three children had both. Interestingly, a statistical 
significant correlation between ASCA IgG and age could be observed, whereas no such relationship was present for ASCA IgA. Clinical features associated with the presence of ASCA were not noticed in this pediatric CF population [13]. Screening sera for several antibodies in 144 adult patients with CF by Lachenal et al. revealed $43.7 \%$ to be positive for ASCA IgA. The presence of this biomarker correlated with both, male sex and hypergammaglobulinaemia. Furthermore, chronic respiratory failure, requested lung transplantation, and fatal outcome were more frequent in CF patients with ASCA IgA or autoantibodies against bactericidal/permeability increasing protein (BPIANCA) [17].

Our data adds further knowledge to the prevalence of anti-glycan antibodies in patients with CF in different age groups. For the first time the results of our single-centre study clearly demonstrate a positive correlation between ASCA and age. Moreover, similar to CD a significant proportion of adult CF patients $(16.9 \%)$ were positive for ASCA and one or even more of three novel serologic anti-glycan antibodies ACCA, ALCA, and AMCA. This phenomenon was found to be in striking difference to other autoimmune diseases such as ulcerative colitis and rheumatoid arthritis as well as to healthy volunteers.

The clinical significance of this autoimmunity in CF remains obscure. No definite clinical symptoms of $\mathrm{CD}$ were detected in the seropositive patients of our CF cohort. However, it has to be mentioned that endoscopic evaluation was not performed in any patient to rule out $\mathrm{CD}$, thus limiting the significance of our study. In addition, there was no correlation between the presence of the anti-glycan antibodies and either gender, inflammation status (as determined by CRP), and the clinical course of CF.

Likewise, whether these antibodies target antigens that have a pathogenic role in CF or whether these markers are barely indicators of increased intestinal permeability remains to be answered. The higher frequency of anti-glycan antibodies in adult patients as compared to pediatric CF patients suggests that the generation of these serologic markers may be rather promoted by longstanding or repeated inflammation and nonspecific immune activation. In contrast, several related studies in CD suggest that the main mechanism for the antibody production might be the loss of the immune tolerance rather than an increase in intestinal permeability $[18,19]$. A lack of correlation between serologic CD phenotypes and intestinal permeability was reported by independent groups, indicating that these markers are not an epiphenomenon related to disease activity [19, 20, 21]. Moreover, an association between $\mathrm{CD}$ and a high serologic response to yeast and mannose as well as a specific lymphocyte reactivity towards mannose compared with the food allergen ovalbumin in ASCA-positive CD patients has been demonstrated $[22,23]$. These data imply that the anti-microorganism response in CD is not merely due to a generalized immunologic hyperreactivity toward intestinal contents as would be expected if intestinal permeability were the main mechanism. Finally, the detection of ASCA in CD patients before clinical diagnosis and the occurrence of antibodies in unaffect- ed first-degree relatives of patients with CD also argue against a leaky bowel theory [21, 24, 25].

To what extent these findings in CD can readily be assigned to $\mathrm{CF}$ and whether the common response to anti-glycan antibodies represents a pathogenetic link for the increased susceptibility of CF patients to CD is unknown to date. In principle, two theories for the increased anti-glycan antibody formation related to the assumed vulnerability of the intestine in CF to develop CD have to be considered. Firstly, increased permeability [26] and impaired protein digestions due to a lack of proteases [27] can lead to a high antigen load to the intestinal mucosa in CF. Secondly, qualitative and quantitative abnormalities in mucus secretion may affect the access and recognition of antigens that cross the mucosal barrier [28]. In that way, Clarke et al. demonstrated in a murine CF model, that Paneth granules undergo limited dissolution and accumulate within the crypts [29]. Among the many antimicrobial effector molecules of Paneth cells defensins have been demonstrated to play a pivotal role in innate immune defence. As anti-glycan antibody formation has been linked to NOD2 mutations in CD which in turn may lead to Paneth cell dysfunction and decreased defensin production [30], it is intriguing to assume that antibody formation in CF might be the result of decreased antimicrobial activity due to decreased defensin secretion. However, this hypothesis has to be scrutinized in further studies.

In conclusion, our study demonstrated for the first time the increased frequency of a panel of anti-glycan antibodies in CF and provided a link between the presence of these serological biomarkers and patient's age. Our findings indicate that ACCA, ALCA, AMCA, and gASCA may be a valuable tool in the care of patients with CF. However, the importance and clinical significance has yet to be determined.

Acknowledgements: The authors are grateful to B. Lafferton and B. Aulbach for excellent technical assistance.

Conflict of interest statement: There was no conflict of interest for any of the authors.

\section{REFERENCES}

1. Farrell PM. Improving the health of patients with cystic fibrosis through newborn screening. Wisconsin Cystic Fibrosis Neonatal Screening Study Group. Adv Pediatr 2000; 47:79-115.

2. Strong TV, Boehm K, Collins FS. Localization of cystic fibrosis transmembrane conductance regulator mRNA in the human gastrointestinal tract by in situ hybridization. J Clin Invest 1994; 93:347-354.

3. Eggermont E. Gastrointestinal manifestations in cystic fibrosis. Eur J Gastroenterol Hepatol 1996; 8:731-738.

4. Wilschanski M. Patterns of gastrointestinal disease associated with mutations of CFTR. Curr Gastroenterol Rep 2008; 10:316-323.

5. Abraham C, Cho JH. Inflammatory bowel disease. $\mathrm{N}$ Engl J Med 2009; 361:2066-2078.

6. Lloyd-Still JD. Crohn's disease and cystic fibrosis. Dig Dis Sci 1994; 39:880-885.

7. Peeters M, Joossens S, Vermeire S, Vlietinck R, Bossuyt $\mathrm{X}$, Rutgeerts P. Diagnostic value of anti-Saccharomyces cerevisiae and antineutrophil cytoplasmic autoantibodies in inflammatory bowel disease. Am J Gastroenterol 2001; 96:730-734. 
8. Zholudev A, Zurakowski D, Young W, Leichtner A, Bousvaros A. Serologic testing with ANCA, ASCA, and anti-OmpC in children and young adults with Crohn's disease and ulcerative colitis: diagnostic value and correlation with disease phenotype. Am J Gastroenterol 2004; 99:2235-2241.

9. Feizi T. Carbohydrate-mediated recognition systems in innate immunity. Immunol Rev 2000; 173:79-88.

10. Dotan I, Fishman S, Dgani Y, Schwartz M, Karban A, Lerner A, et al. Antibodies against laminaribioside and chitobioside are novel serologic markers in Crohn's disease. Gastroenterology 2006; 131:366-378.

11. Ferrante M, Henckaerts L, Joossens M, Pierik M, Joossens S, Dotan N, et al. New serological markers in inflammatory bowel disease are associated with complicated disease behaviour. Gut 2007; 56:1394-1403.

12. Simondi D, Mengozzi G, Betteto S, Bonardi R, Ghignone RP, Fagoonee S, et al. Antiglycan antibodies as serological markers in the differential diagnosis of inflammatory bowel disease. Inflamm Bowel Dis 2008; 14:645-651.

13. Condino AA, Hoffenberg EJ, Accurso F, Penvari C, Anthony M, Gralla J, et al. Frequency of ASCA seropositivity in children with cystic fibrosis. J Pediatr Gastroenterol Nutr 2005; 41:23-26.

14. Rosenfeld M, Davis R, FitzSimmons S, Pepe M, Ramsey B. Gender gap in cystic fibrosis mortality. Am J Epidemiol 1997; 145:794-803.

15. Papp M, Altorjay I, Dotan N, Palatka K, Foldi I, Tumpek J, et al. New serological markers for inflammatory bowel disease are associated with earlier age at onset, complicated disease behavior, risk for surgery, and NOD2/ CARD15 genotype in a Hungarian IBD cohort. Am J Gastroenterol 2008; 103:665-681.

16. Henckaerts L, Pierik M, Joossens M, Ferrante M, Rutgeerts $\mathrm{P}$, Vermeire $\mathrm{S}$. Mutations in pattern recognition receptor genes modulate seroreactivity to microbial antigens in patients with inflammatory bowel disease. Gut 2007; 56:1536-1542.

17. Lachenal F, Nkana K, Nove-Josserand R, Fabien N, Durieu I. Prevalence and clinical significance of auto-antibodies in adults with cystic fibrosis. Eur Respir J 2009; 34:1079-1085.

18. Vasiliauskas EA, Plevy SE, Landers CJ, Binder SW, Ferguson DM, Yang $\mathrm{H}$, et al. Perinuclear antineutrophil cytoplasmic antibodies in patients with Crohn's disease define a clinical subgroup. Gastroenterology 1996; 110:18101819.

19. Harrer M, Reinisch W, Dejaco C, Kratzer V, Gmeiner M, Miehsler W, et al. Do high serum levels of anti-Saccharomyces cerevisiae antibodies result from a leakiness of the gut barrier in Crohn's disease? Eur J Gastroenterol Hepatol 2003; 15:1281-1285.

20. Vermeire S, Peeters M, Vlietinck R, Joossens S, Den Hond E, Bulteel V, et al. Anti-Saccharomyces cerevisiae antibodies (ASCA), phenotypes of IBD, and intestinal permeability: a study in IBD families. Inflamm Bowel Dis 2001; 7:8-15.

21. Israeli E, Grotto I, Gilburd B, Balicer RD, Goldin E, Wiik A, et al. Anti-Saccharomyces cerevisiae and antineutrophil cytoplasmic antibodies as predictors of inflammatory bowel disease. Gut 2005; 54:1232-1236.
22. Lindberg E, Magnusson KE, Tysk C, Järnerot G. Antibody (IgG, IgA, and IgM) to baker's yeast (Saccharomyces cerevisiae), yeast mannan, gliadin, ovalbumin and betalactoglobulin in monozygotic twins with inflammatory bowel disease. Gut 1992; 33:909-913.

23. Konrad A, Rütten C, Flogerzi B, Styner M, Göke B, Seibold F. Immune sensitization to yeast antigens in ASCApositive patients with Crohn's disease. Inflamm Bowel Dis 2004; 10:97-105.

24. Seibold F, Slametschka D, Gregor M, Weber P. Neutrophil autoantibodies: a genetic marker in primary sclerosing cholangitis and ulcerative colitis. Gastroenterology 1994; 107:532-536.

25. Sutton CL, Yang H, Li Z, Rotter JI, Targan SR, Braun J. Familial expression of anti-Saccharomyces cerevisiae mannan antibodies in affected and unaffected relatives of patients with Crohn's disease. Gut 2000; 46:58-63.

26. Leclercq-Foucart J, Forget PP, Van Cutsem JL. Lactulose-rhamnose intestinal permeability in children with cystic fibrosis. J Pediatr Gastroenterol Nutr 1987; 6:6670.

27. Hsieh MC, Berry HK. Protease inhibitor and defective proteolysis in cystic fibrosis. Dig Dis Sci 1988; 33:282288.

28. Slomiany A, Liau YH, Carter SR, Newman LJ, Slomiany BL. Mucus glycoprotein fatty acyltransferase in patients with cystic fibrosis: effect on the glycoprotein viscosity. Biochem Biophys Res Commun 1985; 132:299-306.

29. Clarke LL, Gawenis LR, Bradford EM, Judd LM, Boyle KT, Simpson JE, et al. Abnormal Paneth cell granule dissolution and compromised resistance to bacterial colonization in the intestine of CF mice. Am J Physiol Gastrointest Liver Physiol. 2004; 286:G1050-1058.

30. Wehkamp J, Harder J, Weichenthal M, Schwab M, Schäffeler E, Schlee M, et al. NOD2 (CARD15) mutations in Crohn's disease are associated with diminished mucosal alpha-defensin expression. Gut. 2004; 53:1658-1664.

Received: December 20, 2010 / Accepted: May 24, 2011

Address for correspondence:

Tim O. Hirche

Department of Pulmonary Medicine

German Clinic for Diagnostics

Aukammallee 33

65191 Wiesbaden

Germany

E-mail: tim.hirche@dkd-wiesbaden.de

Oliver Schröder

1st Department of Internal Medicine

Division of Gastroenterology and Hepatology

Johann Wolfgang Goethe-University Hospital Frankfurt

Theodor Stern Kai 7

60590 Frankfurt

Germany

Tel.: $\quad+49-69-6301-87679$

Fax: +49-69-6301-6448

E-mail: o.schroeder@em.uni-frankfurt.de 